\title{
C.C. Ипполитов
}

\section{"Я ВИАЕА MEРТВЫХ...": РОССИЙСКОЕ ОБЩЕСТВО КРАСНОГО КРЕСТА И АМЕРИКАНСКИЙ КРАСНЫЙ КРЕСТ В СИБИРИ И НА ААИЬНЕМ ВОСТОКЕ В 1918-1920 rr.}

Аннотация. На основе не исследованных ранее архивных документов, впервые введенных в научный оборот, автор исследовал малоизвестную странииу Гражданской войны в России: деятельность Российского общества Красного Креста в Сибири и на Дальнем Востоке и его взаимодействие с иностранными благотворительными организациями. В статье впервые в отечественной историографии изучено взаимодействие российских и иностранных благотворительных организаций в деле создания работающей системь оказания помощи больным и раненым в условиях деградации и развала государственного управления на территориях, подконтрольных правительству А.В. Колчака в 1918-1920 г2.

Ключевые слова: Гражданская война в России, Российское общество Красного Креста, Американский Красный Крест, Александр Васильевич Колчак, правительство адмирала Колчака, Сибирь, Дальний Восток России, благотворительная деятельHость.

Ипполитов Сергей Сергеевич - кандидат исторических наук, проректор по развитию Московского государственного института культуры. E-mail: nivestnik@yandex.ru

S.S. Ippolitov. «I Saw Dead...»: The Russian Red Cross and the American Red Cross in Siberia and the Far East in 1918-1920

Abstract. Basing on archival documents, not studied before and now introduced into scientific circulation, the author examines the unfamiliar page of the Civil war in Russia: the Russian society of the Red Cross in Siberia and the Far East and its interaction with foreign charitable organizations. For the first time in Russian historiography the article describes the interaction of Russian and foreign charitable organizations in creating the medical care system for sick and wounded in conditions of degradation and collapse of the state control on the territories, governed by A.V. Kolchak in 1918-1920. 
Keywords: the Civil war in Russia, the Russian society of the Red Cross, the American Red Cross, Alexander Vasilievich Kolchak, the government of Admiral Kolchak, Siberia, the Far East of Russia, charity.

Ippolitov Sergey Sergeevich - Candidate of History,

vice rector for development of Moscow State Art

and Cultural University. E-mail: nivestnik@yandex.ru

Восстановление деятельности Российского общества Красного Креста на территориях, находившихся под контролем контрреволюционных режимов, стало определенной вехой Гражданской войны в России. Это событие ознаменовало собой не просто возобновление медицинской помощи больным и раненым участникам боевых действий. Значение и смысл этого события были гораздо глубже. Наряду с попытками - когда более, когда менее удачными - создавать структуры государственного управления на неподконтрольных большевистской власти территориях, воссоздание деятельности РОКК стало попыткой возродить общественные структуры, элементы гражданского общества, которые, казалось, безвозвратно исчезли в мясорубке братоубийственной войны. В жестокости военных действий, в разрухе, воровстве и хаосе тыловой жизни [1, с. 101-121] российские общественные благотворительные организации предприняли попытку создать действенный механизм помощи нуждающимся.

Вся деятельность РОКК в рассматриваемый период была тесно связана с зарубежными миссиями российского Красного Креста, которые приобрели в условиях Гражданской войны особое значение. Через них осуществлялась связь с иностранными Красными Крестами, другими общественными благотворительными организациями, оказывавшими помощь России. Конечно, нельзя сказать, что эта помощь текла широкой рекой, но она была очень существенна, а в условиях сильнейшей инфляции к концу 1919 г. и оскудения внутреннего рынка просто необходима. Кроме того, за границей на 1917 1918 гг. оставалось большое имущество Красного Креста, в котором остро нуждались воссозданные организации в Омске и Екатеринбурге. Обоснованием же законности претензий на это имущество, их юридическим оформлением должны были заниматься именно зарубежные миссии РОКК. Уже в марте 1919 г. появилась на свет секретная телеграмма российского посла в Париже В.А. Маклакова, где он информировал адмирала Колчака о многомиллионном имуществе военно-санитарного ведомства, Красного Креста и Земгора за границей с просьбой разрешить распределение этого имущества между Сибирью, югом и севером России [3, л. 31].

Но Маклаков несколько поторопился с планом распределения имущества. В своих расчетах он опирался на признание 16 марта ВГУ РОКК Женевским Постоянным Международным Бюро Красного Креста [3, л. 1]. 
Однако для полного возобновления юридического бытия необходимо было добиться признания Временного Главного управления Международным комитетом Красного Креста. В июле 1919 г. в Женеве рассматривался вопрос, кого считать всероссийским Красным Крестом [4, л. 31]. В результате были выработаны условия, на которых Временное Главное управление РОКК в Омске могло быть признано таковым. 29 июля секретная телеграмма с изложением этих условий, отправленная из Парижа С.Д. Сазоновым, министром иностранных дел правительства Колчака, была получена в Омске. Сводились они к следующему:

«1. Омское Правительство должно было заявить графу Игнатьеву в Париже, что считает преемником признанного Российского Креста:

a) Главный Крест в совокупном составе членов старого Главного Креста,

б) Омский Главный Крест,

в) Екатеринодарское Управление Креста...

2. Главный Крест должен возбудить перед Женевским Международным Комитетам ходатайство о признании, удостоверенное возможно большим числом членов Главного Красного Креста, особенно предыдущего состава» $[5$, л. 73,75$]$.

Необходимо отметить, что иностранная помощь российским санитарным учреждениям вообще, и Красному Кресту, в частности, летом-осенью 1919 г. была необходима как никогда. Положение антибольшевистских сил в Сибири и на Дальнем Востоке становилось катастрофическим. При общем развале фронта и тылового управления сильнее всего страдали наименее защищенные - раненые, чье положение было особенно трагичным. Вот что отмечал в своем дневнике А.П. Будберг, бывший на тот момент времени военным министром правительства А.В. Колчака, 28 августа 1919 г.: «Много кричат о плохом уходе, но никто не идет в санитары и сиделки, хотя тыл переполнен здоровыми балбесами и безработными женщинами; еще больше говорят о грязном и рваном белье, но я не слышал, чтобы где-нибудь образовался добровольный кружок, который взял бы на себя мойку и починку белья. Я как-то указал начальнику санитарно-эвакуационной части на недопустимость возить раненых на двуколках без подстилки и узнал при этом, что все затруднение в том, что кто-то не может купить соломы по предельной цене, для нее установленной; сего контрольного буквоедства оказалось достаточным, чтобы сложить ручки и таскать искалеченных раненых по омским ухабам» $[6$, с. 138$]$.

16 августа 1919 г. условия были приняты, граф П.Н. Игнатьев назначен главноуполномоченным РОКК для заграницы [7, л. 78]. Международный комитет Красного Креста в Женеве в конце концов согласился поддерживать официальные отношения с ВГУ РОКК, но последнему еще не раз приходилось отстаивать свой статус. Это необходимо было сделать и на Между- 
народном Конгрессе в Женеве, где присутствовали представители Советского Красного Креста, и осенью 1919 г., когда из-за начавшегося отступления Колчака и оставления им больших территорий Игнатьеву пришлось возбуждать ходатайство перед Международным комитетом о «непрекращении юридического бытия национального РОКК вне территорий, занятых большевиками» $[8$, л. 310$]$.

Круг вопросов, находившихся в ведении зарубежных миссий, не ограничивался решением юридических проблем и представительскими функциями. Как уже говорилось выше, они являлись центрами, в которых сосредоточивалась и которыми координировалась значительная часть иностранной помощи. Поэтому ВГУ, кровно в этой помощи заинтересованное, делало все для обеспечения стабильности их работы. Непосредственно Омским Временным Главным управлением финансировалось шесть европейских миссий: в Париже, Швейцарии, Польше, Чехословакии, Лондоне, Стокгольме, миссии в Иокогаме и Вашингтоне. Представление о размерах субсидий для них дает тот факт, что только с 1 сентября 1919 по 1 января 1920 г. на их содержание было отпущено (в суммарном пересчете на рубли) около 37 млн [9, л. 7-8]. Если учесть, что на содержание самого ВГУ и всех подведомственных ему учреждений за весь 1919-й год было израсходовано в рублевом выражении более 28 млн руб. при общем балансе в 65 млн, становится понятным значение, этим миссиям придаваемое. За четыре месяца зарубежные представительства израсходовали около 56\% средств, необходимых для финансирования деятельности РОКК в течение года.

Тесные связи существовали с китайской миссией в Харбине; ею содержался санаторий для выздоравливающих. Всего же в документах за 1918 1919 гг. из фонда ВГУ и личного фонда М.Л. Киндякова имеются ссылки на 18 зарубежных миссий РОКК, действовавших в этот период. Ключевую роль впоследствии суждено было сыграть одной из них - Константинопольской, которая, начиная с 1920 г., с момента прибытия в Турцию основной массы российских эмигрантов, стала одним из главных центров российских общественных организаций в эмиграции. Миссия РОКК вошла составной частью в Центральный Объединенный комитет Всероссийского Земского Союза, Всероссийского Союза городов и Российского общества Красного Креста.

Однако ни самая активная помощь заграницы, ни собственные закупочные экспедиции ВГУ не могли обеспечить четкое функционирование всех его учреждений.

Характерно, что идея создания небольших производств, который могли бы, с одной стороны, давать средства для благотворительной деятельности, a c другой - удовлетворять острейший голод в производственных товарах и услугах на территории Сибири и Дальнего Востока, отнюдь не являлась эксклюзивным изобретением РОКК. Так, уполномоченный Шведского кон- 
сульства г. Омска по делам германских и турецких военнопленных 16 мая 1919 г. писал следующее: «Проживающие в лагерях военнопленные офицеры и солдаты обратились... с просьбой об оказании им содействия в деле получения... разрешения на устройство мастерских в отдельных лагерях Иркутского Военного округа. С одной стороны, офицеры вовсе не подлежат принудительной посылке на работы за пределы лагеря, а большинство остающихся теперь в лагерях солдат - инвалиды или же по иным причинам неспособны к труду вне лагеря. Предоставление им возможности заниматься в пределах лагеря каким-либо мастерством внесло бы некоторое разнообразие в тяжелую лагерную жизнь и оказало бы благотворное влияние на психику заключенных. С другой стороны, происходящие в политической жизни Центральной Европы события не дают надежды на получение Шведским Красным Крестом в дальнейшем сумм, достаточных для оказания материальной поддержки военнопленным в прежнем размере. Наконец, говорить об опасной для русских рабочих конкуренции со стороны предполагаемых к открытию мастерских, на наш взгляд, не приходится, ибо местное производство, как известно, совершенно не в состоянии удовлетворить острую нужду местного населения во всех предметах домашнего обихода и ремесленных изделиях. Таковые теперь приходится ввозить по бешеным ценам с Востока. Между тем многие из таких изделий: столярные, кузнечные, кожаные могли бы при большом количестве опытных мастеров среди военнопленных быть изготовляемы в лагерях по ценам гораздо более низким, чем нынешние рыночные» [10, л. 271].

Весной 1919 г. родилась идея об объединении заграничной помощи. 12 мая в Омск была направлена телеграмма от поверенного в делах в Вашингтоне С.А. Угета, в которой высказано предложение об объединении заграничной благотворительности, приведя ее в связь с деятельностью ВГУ и о необходимости создания для этого в «главнейших странах» центральных комитетов помощи России [11, л. 45]. 14 июня, не удовлетворившись, видимо ходом объединительного процесса, С.А. Угет отправил еще одну подобную телеграмму, но уже на имя министра иностранных дел $[12$, л. 9].

Объединение зарубежной благотворительности началось 30 мая 1919 г. с открытия в Лондоне Комитета российского Красного Креста в Великобритании для помощи раненым и беженцам из Сибири, Архангельска и Дона. Лондонский комитет находился под опекой трех именитых покровителей: Королевы Александры, герцога Корноутского и принцессы ЕленыХристинес. На посту Президента находился Председатель Британского Красного Креста сэр Артур Станлей. Бюро воззваний возглавляла супруга премьер-министра г-жа Ллойд-Джорж. После президента в структуру Лондонского Комитета, в порядке убывания, входили вице-президент, главный комитет, исполнительный комитет, который в свою очередь осуществлял 
руководство Британским комитетом Красного Креста, Бюро Красного Креста, ведавшее помощью беженцам, пленным, связями с прессой, транспортным обеспечением. Исполнительный комитет был также напрямую связан с Главным Управлением РОКК через его главноуполномоченного [43, с. 57]. Характерно, что первый транспорт, сформированный Комитетом, предполагалось отправить в Петроград [13, л. 113].

7 июня 1919 г. состоялось слушание на заседании исполнительной комиссии ВГУ РОКК вопроса об организации российского Комитета помощи в заграничных странах в интересах уполномоченных Красного Креста и под их контролем, но на автономных началах $[14$, л. 38], а 30 июня Министерством иностранных дел для ВГУ получена секретная телеграмма российского посла в Париже об установлении контакта с Политическим совещанием и создававшимся Комитетом объединения помощи русским за границей, целью которого ставилось приведение в порядок обособленной деятельности представителей различных областей работников «старого Креста» $[15$, л. 5].

Необходимо отметить, что Российский Красный Крест принимал участие в жизни Международного Красного Креста и помимо работы по сбору пожертвований. В апреле в Каннах открылась Всемирная конференция специалистов по инициативе Комитета общества Красного Креста, на которой была выработана программа и организован Международный совет и Бюро гигиены и общественного здравия. Полномочия ВГУ на участие в конференции были возложены на особоуполномоченного Голубева $[16$, л. 58]; в июле начата подготовка к Международному конгрессу Красного Креста, на который Временным Главным управлением для представительства РОКК был назначен Ю.В. Ключников [17, л. 193]. В этом же месяце состоялось объединение всех организаций РОКК под единым началом. 29 июля в Париже прошло совещание по делам РОКК под председательством графа П.Н. Игнатьева, на которого было возложено общее руководство деятельностью представительства РОКК за границей при содействии совещания из членов Главного управления $[18$, л. 7$]$.

Таким образом, к лету 1919 г. можно было говорить о существовании в мире целого ряда благотворительных организаций, в своей деятельности ориентированных на оказание помощи России, ведущую роль в объединении которых сыграло Временное Главное управление РОКК посредством своих зарубежных миссий. Далеко не всегда эта помощь носила бескорыстный характер, что просматривалось иногда в деятельности иностранных Красных Крестов на территории России, особенно Американского Красного Креста, однако значение ее для судеб многих и многих соотечественников было достаточно велико.

Первый документ о взаимодействии Омского ВГУ с иностранными Красными Крестами на территории России датируется 25 февраля 1919 г., 
когда из Стокгольма от поверенного в делах Бэре на имя министра иностранных дел была отправлена секретная телеграмма с просьбой о свободном пропуске и оказании содействия делегатам Датского Красного Креста, ехавшим из Петрограда (в источнике Петербург) в Омск по делу о германских военнопленных. В качестве аргумента упоминалось о помощи Датского Красного Креста российским военнопленным и заключенной в Петроградских и московских тюрьмах интеллигенции [19, л. 15].

ВГУ являлось основным официальным институтом, распоряжавшимся зарубежной помощью, обеспечивавшим проезд иностранных миссий и поставлявшим кадры в учреждения этих миссий. Так, в марте 1919 г. МИД обратилось в ВГУ с просьбой предоставить возможность бесплатного проезда 20 делегатам Комитета соединенных скандинавских Красных Крестов [20, л. 107], а в августе ВГУ была получена вербальная нота японской дипломатической миссии в Сибири о беспошлинном провозе санитарных материалов для жителей Сибири (3240 ящиков весом 5500 пудов) и об установлении непосредственных отношений этой миссии с РОКК [21, л. 351].

С подобными просьбами обращались Британский и Американский Красные Кресты [22, л. 59]. Британским же Красным Крестом был сформирован санитарный отряд, который в документах упоминается как «российский отряд Британского Красного Креста» [23, л. 141] и Англо-российский госпиталь в Екатеринбурге [24, л. 117].

Контакты Российского общества Красного Креста с иностранными Красными Крестами были, конечно, намного шире, но сведений о них в наших архивах, к сожалению, не найдено. Хотя документы такие существуют. Доказательством может служить список дел по общей канцелярии ВГУ, где, среди прочих, упоминаются материалы о сношениях с Японией, Британским, Канадским, Американским и Северными Красными Крестами [25, л. 36], причем это были, очевидно, не единичные документы, а целые дела.

Гораздо более полно в источниках отражена деятельность Американского Красного Креста, и не только в силу их сохранности, но и благодаря масштабам помощи последнего. В нескольких документах фонда ВГУ РОКК имеются карандашные памятки авторов, типа «смотрите дело (или журналы) Американского Красного Креста» [26, л. 117], которые дают основание предполагать существование богатой источниковой базы для исследования. Самих журналов и отчетов найти не удалось. Можно предположить, что они не были переданы нашей стране в составе Пражского архива и хранятся сейчас в США, но и имеющиеся в нашем распоряжении создают довольно полную картину деятельности этой организации в России. Уже в марте 1919 г. им направлена в Сибирь крупная партия медикаментов. Сохранилось ходатайство американцев о бесплатном провозе по сибирским железным дорогам грузов Красного Креста для бесплатного распределения между беженцами и граж106 
данским населением Сибири [27, л. 24]; а еще раньше, в феврале, ими оказывалась помощь в ликвидации последствий эпидемии - 24 февраля князь Голицын обратился к Американскому Красному Кресту с просьбой о превращении госпиталя в Тюмени, ему принадлежащего, в сыпнотифозный из-за переполнения госпиталей РОКК [28, л. 12].

Наиболее крупные масштабы помощь Америки приобрела в июлеавгусте 1919 г. В июле упоминалось об Отделе призрения беженцев Западной Сибири Американского Красного Креста [29, л. 225]; тогда же началась подготовка плана совместной деятельности Российского и Американского Красного Крестов. 21 июля в ВГУ поступило отношение Министерства иностранных дел с копией телеграммы Угета, сообщавшей о желании Америки оказать разностороннюю помощь РОКК [30, л. 64]. Спустя пять дней в Сибирь из Америки была отправлена очередная партия медикаментов и санитарных принадлежностей [31, л. 82]. 29 июля - новая телеграмма Угета, на этот раз о намерении Американского Красного Креста до сентября выслать в Сибирь 7 тыс. т медикаментов [32, л. 58]. В конце месяца в телеграмме ВГУ на имя Президента Северо-Американских Соединенных Штатов план санитарной помощи начал упоминаться в настоящем времени: «Российский Красный Крест, осведомившись о том, что Красный Крест Соединенных Штатов... предоставил на Ваше усмотрение план санитарно-медицинской помощи Сибири, считает своим долгом заявить Вам как председателю Красного Креста, что таковая помощь... необходима для Сибири и будет принята с чувством искренней благодарности» [33, л. 13]. И наконец, 24 августа Временное Главное управление получило по телеграфу доклад В.Е. Буймистрова о предоставлении Американским Красным Крестом Президенту ходатайства о выдаче средств на организацию санитарной компании в целях ограждения великого Сибирского пути от эпидемии [34, л. 96]. В результате к сентябрю 1919 г. можно было говорить об определенной ориентации Временного Главного управления на помощь Америки и ее Красного Креста, что нашло свое отражение в планах тесного увязывания деятельности РОКК и Американского Красного Креста. Шел процесс сближения ВГУ и американской военной миссии, активизировалась переписка с Вашингтоном, а 15 сентября на заседании исполнительной комиссии даже был поставлен вопрос об издании англо-российского военно-технического словаря [35, л. 133].

Сами американцы всячески подчеркивали бескорыстность своей помощи и независимость ее от политики. Уполномоченный Сибирской комиссии Американского Красного Креста доктор Манже, определяя ее статус, подчеркивал, что Сибирская комиссия «является организацией неправительственной, работа которой не связана с другими организациями союзных государств, не имеет обязательного характера и не продиктована политическими, дипломатическими и иными соображениями и что помощь, оказываемая 
русскому народу, является помощью американского народа, вызванной исключительно одними чувствами человеколюбия...» [36, л. 411].

Вот как описывал увиденное в Сибири сотрудник Американского Красного Креста Рудольф Бьюкели, оставивший драматические воспоминания «Поезд смерти»: «Я видел мертвых, тела которых болезни и паразиты разъедали до тех пор, пока жизнь не покинула их после 5 месяцев ежедневной мучительной пытки от голода, грязи и холода. Клянусь богом, я не преувеличиваю. Через окна товарных вагонов размером 24 фута на 10, я видел животных, которые когда-то были людьми, мужчинами, женщинами и детьми; на меня глядели лица, в которых я не мог признать человеческие существа. Они были подобны мордам животных, неизвестной людям породы. Полнейшее безумие и ужас смотрели на меня из их глаз, и на всем лежали знаки смерти, ошибаться в которых было невозможно» [2, с. 136].

Действительно, участие Американского Красного Креста в помощи больным и раненым в Сибири в период Гражданской войны хорошо известно и задокументировано.

Однако человеколюбивая риторика, которой были наполнены отчеты и воспоминания деятелей Американского Красного Креста, не всегда имела реальных оснований. Тесное взаимодействие между Красными Крестами и широкомасштабная помощь американцев продлилась лишь до середины сентября 1919 г., когда армии адмирала Колчака начали терпеть одно поражение за другим. С этого момента характер деятельности Американского Красного Креста существенно меняется. Слишком опасно, да и незачем было связывать себя с режимом, который мог в скором времени пасть.

Анализ деятельности Американского Красного Креста на территории Сибири и Дальнего Востока дает основание предполагать, что, помимо оказания медицинской помощи русскому населению, он преследовал еще и иные, далеко не благотворительные, цели. Учитывая огромный интерес во всем мире к событиям в России, нельзя было не увидеть, что любая помощь ей будет являться прекрасной рекламой организации, эту помощь осуществлявшей [44, с. 38]. Поддержка России стала своего рода бизнесом, приносящим как политический, так и обычный капитал в денежном выражении. Второй активно накапливался в Америке, где несколько посреднических агентств осуществляли отправку в Россию продовольственных посылок, деньги на которые вносились российскими эмигрантами для своих родственников [46, л. 102]. Сложнее было приобрести капитал политический, сохранив при этом максимально возможный нейтралитет, что с успехом удалось Американскому Красному Кресту, во многом в ущерб своей основной деятельности. 23 сентября 1919 г. ВГУ рассматривался доклад помощника уполномоченного во Владивостоке доктора П.В. Захарова о деятельности американцев в этом городе. Он сообщал о характере работы Американского Красного Креста, 108 
которая сводилась, по его описанию, «к рекламированию своей деятельности, вместо действительно широкой помощи населению (курсив мой. Aвm.). Не отказываясь на словах в согласии осуществлять помощь русскому Красному Кресту и вести с ним совместную работу, американцы на деле ограничили свою помощь крайне незначительным количеством медикаментов, хирургических инструментов и материалов, а вместо совместной деятельности резко сократили свою работу в особых госпиталях, заняв для них лучшие помещения и принимая все меры к тому, чтобы вся деятельность их протекала исключительно под флагом Американского Красного Креста. В этой их деятельности появился план работы, имевший целью оказать материальную помощь населению Сибири, по возможности минуя российские государственные и благотворительные учреждения» [38, л. 165]. Действительно, подобные обвинения имели основания. 7 мая появилось упоминание об отказе Американского Красного Креста оказать обещанную помощь и невозможность в связи с этим формирования Приамурским окружным управлением подвижного лазарета [39, л. 138]; в июле 1919 г., в разгар боевых действий на фронте и при острой нехватке медицинского персонала из Архангельска выехала на родину работавшая там организация Американского Красного Креста, что потребовало возобновления деятельности Российского Красного Креста в северной области [40, л. 52].

Подобная линия Американского Красного Креста, направленная на обособление своей деятельности от существовавших в Сибири государственных и общественных формирований, попытка автономной работы имела успех, доказательством чего является тот факт, что Американский Красный Крест был избран посредником при обращении Советской власти к Омскому Правительству, когда из Царского Села пришло обращение Центрального Комитета Российского Красного Креста к Американскому с просьбой о ходатайстве перед Омским Правительством разрешения на приобретение и вывоз зерна из территорий, находившихся под властью Комитета членов Учредительного собрания для помощи голодающим детям Советской Республики (Обращение было подписано председателем ЦК Российского Красного Креста Вениамином Свердловым и главноуполномоченным Датского Красного Креста в России Мартини $[41$, л. 2-5]); и в период пребывания у власти в Иркутске Политического центра, когда Американский Красный Крест выступал посредником при передаче ему имущества РОКК [42, л. 60].

На мысль о попытке политизировать краснокрестную деятельность наводят два значительных факта: визит 28 апреля на заседание исполнительной комиссии ВГУ начальника военной миссии майора Слоттера [43, л 73], и появление в газете американского Бюро печати в связи с несанкционированной поездкой доктора Соколова в Америку, просьбы оказать России помощь «в борьбе за восстановление порядка в России» [44, л. 260]. 
Исполнительной комиссией по второму факту было принято специальное заявление о том, что подобные высказывания «противоречат аполитичной краснокрестной деятельности» [45, л. 260]. На основании этих событий, конечно, нельзя делать вывод о втягивании РОКК в сферу политики, но подобное предположение в отношении Американского Красного Креста выглядит вполне реальным.

Работа российских благотворительных организаций на территории Сибири и Дальнего Востока в этот период протекала в тесном контакте с иностранными организациями, внесшими заметный вклад в дело помощи жертвам Гражданской войны в России [45, с. 102].

И все же, несмотря на эти специфические черты в работе Американского Красного Креста в 1919 г. на территории России, значение сотрудничества российской и американской краснокрестных организаций велико и духовный потенциал, накопленный в процессе совместной деятельности, весьма ценен.

\section{Библиография}

1. Будберг А.П. Дневник белогвардейца. Минск: Харвест, М.: АСТ, 2001. 270 с.

2. Бьюкели Р. Поезд смерти / Поезд смерти. Куйбышев: Куйбышевское книжное издательство, $1960.156 \mathrm{c}$.

3. ГАРФ. Ф. 1845. Оп. 1. Д. 12.

4. ГАРФ. Ф. 1845. Оп. 1. Д. 12.

5. ГАРФ. Ф. 1845. Оп. 1. Д. 12.

6. ГАРФ. Ф. 1845. Оп. 1. Д. 12.

7. ГАРФ. Ф. 1845. Оп. 1. Д. 12.

8. ГАРФ. Ф. 1845. Оп. 1. Д. 12.

9. ГАРФ. Ф. 1845. Оп. 1. Д. 12.

10. ГАРФ. Ф. 1845. Оп. 1. Д. 12.

11. ГАРФ. Ф. 1845. Оп. 1. Д. 12.

12. ГАРФ. Ф. 1845. Оп. 1. Д. 13.

13. ГАРФ. Ф. 1845. Оп. 1. Д. 13.

14. ГАРФ. Ф. 1845. Оп. 1. Д. 16.

15. ГАРФ. Ф. 1845. Оп. 1. Д. 7, 191.

16. ГАРФ. Ф. 1845. Оп. 1. Д. 21.

17. ГАРФ. Ф. 1845. Оп. 1. Д. 21.

18. ГАРФ. Ф. 1845. Оп. 1. Д. 32.

19. ГАРФ. Ф. 1845. Оп. 1. Д. 32.

20. ГАРФ. Ф. 1845. Оп. 1. Д. 39.

21. ГАРФ. Ф. 1845. Оп. 1. Д. 43.

22. ГАРФ. Ф. 1845. Оп. 1. Д. 57.

23. ГАРФ. Ф. 1845. Оп. 1. Д. 57.

24. ГАРФ. Ф. 1845. Оп. 1. Д. 57.

25. ГАРФ. Ф. 1845. Оп. 1. Д. 57.

26. ГАРФ. Ф. 1845. Оп. 1. Д. 57.

27. ГАРФ. Ф. 1845. Оп. 1. Д. 57.

28. ГАРФ. Ф. 1845. Оп. 1. Д. 57. 
29. ГАРФ. Ф. 1845. Оп. 1. Д. 57.

30. ГАРФ. Ф. 1845. Оп. 1. Д. 57.

31. ГАРФ. Ф. 1845. Оп. 1. Д. 57.

32. ГАРФ. Ф. 1845. Оп. 1. Д. 57.

33. ГАРФ. Ф. 1845. Оп. 1. Д. 57.

34. ГАРФ. Ф. 1845 . Оп. 1. Д. 6.

35. ГАРФ. Ф. 1845. Оп. 1. Д. 6.

36. ГАРФ. Ф. 1845 . Оп. 1. Д. 6.

37. ГАРФ. Ф. 1845. Оп. 1. Д. 7.

38. ГАРФ. Ф. 1845. Оп. 1. Д. 7.

39. ГАРФ. Ф. 1845. Оп. 1. Д. 70.

40. ГАРФ. Ф. 1845 . Оп. 1. Д. 8.

41. ГАРФ. Ф. 1845. Оп. 1. Д. 9.

42. ГАРФ. Ф. 1845. Оп. 1. Д. 7.

43. Ипполитов С.С. Российское общество Красного Креста в Сибири и на Дальнем Востоке: организация и помощь армии и населению (1919-1920 гг.) // Новый исторический вестник. 2013. № 1 (35). С. 56-68.

44. Ипполитов С.С., Минаев В.В. «От этого зависит вся судьба России»: К изучению демографической и экономической экспансии Китая и Японии на востоке России во время Второй русской смуты // Новый исторический вестник. 2013. № 3 (37). С. 38-39.

45. Карпенко С.В. Экономический кризис и коррупция: Из истории тыла белых армий Юга России (1918-1920 гг.) // Экономический журнал. 2015. № 2 (38). С. 101-121.

46. Кокоулин В.Г. «От мала до велика спекулируют на чем только возможно»: Городские рынки в «белой» Сибири (1918-1919 гг.) // Новый исторический вестник. 2012. № 3 (33). C. $94-109$.

47. РГВА. Ф. 39515. Оп. 1. Д. 304. Л. 271.

48. Черниченко М.Ю. Кризис денежного обращения в тылу войск генерала А.И. Деникина в освещении печати Белого юга России (1919 г.) // Новый исторический вестник. 2014. № 1 (39). C. 70-88.

\section{References} $156 \mathrm{p}$.

B'jukeli R. Poezd smerti / Poezd smerti. Kujbyshev: Kujbyshevskoe knizhnoe izdatel'stvo, 1960.

Budberg A.P. Dnevnik belogvardejca. Minsk: Harvest, Moscow: AST, 2001. 270 p.

Chernichenko M.Ju. Krizis denezhnogo obrashhenija v tylu vojsk generala A.I. Denikina v osveshhenii pechati Belogo juga Rossii (1919 g.) // Novyj istoricheskij vestnik. 2014. N 1 (39). P. $70-88$.

GARF. F. 1845. Op. 1. D. 12.

GARF. F. 1845. Op. 1. D. 12.

GARF. F. 1845. Op. 1. D. 12.

GARF. F. 1845. Op. 1. D. 12.

GARF. F. 1845. Op. 1. D. 12.

GARF. F. 1845. Op. 1. D. 12.

GARF. F. 1845. Op. 1. D. 12.

GARF. F. 1845. Op. 1. D. 12.

GARF. F. 1845. Op. 1. D. 12.

GARF. F. 1845. Op. 1. D. 13. 
GARF. F. 1845. Op. 1. D. 13.

GARF. F. 1845. Op. 1. D. 16.

GARF. F. 1845. Op. 1. D. 7, 191.

GARF. F. 1845. Op. 1. D. 21.

GARF. F. 1845. Op. 1. D. 21.

GARF. F. 1845. Op. 1. D. 32.

GARF. F. 1845. Op. 1. D. 32.

GARF. F. 1845. Op. 1. D. 39.

GARF. F. 1845. Op. 1. D. 43.

GARF. F. 1845. Op. 1. D. 57.

GARF. F. 1845. Op. 1. D. 57.

GARF. F. 1845. Op. 1. D. 57.

GARF. F. 1845. Op. 1. D. 57.

GARF. F. 1845. Op. 1. D. 57.

GARF. F. 1845. Op. 1. D. 57.

GARF. F. 1845. Op. 1. D. 57.

GARF. F. 1845. Op. 1. D. 57.

GARF. F. 1845. Op. 1. D. 57.

GARF. F. 1845. Op. 1. D. 57.

GARF. F. 1845. Op. 1. D. 57.

GARF. F. 1845. Op. 1. D. 57.

GARF. F. 1845. Op. 1. D. 6.

GARF. F. 1845. Op. 1. D. 6.

GARF. F. 1845. Op. 1. D. 6.

GARF. F. 1845. Op. 1. D. 7.

GARF. F. 1845. Op. 1. D. 7.

GARF. F. 1845. Op. 1. D. 7.

GARF. F. 1845. Op. 1. D. 70.

GARF. F. 1845. Op. 1. D. 8.

GARF. F. 1845. Op. 1. D. 9.

Ippolitov S.S. Rossijskoe obshhestvo Krasnogo Kresta v Sibiri i na Dal'nem Vostoke: Organizacija i pomoshh' armii i naseleniju (1919-1920 gg.) // Novyj istoricheskij vestnik. 2013. N 1 (35). P. 56-68.

Ippolitov S.S., Minaev V.V. «Ot jetogo zavisit vsja sud'ba Rossii»: K izucheniju demograficheskoj i jekonomicheskoj jekspansii Kitaja i Japonii na vostoke Rossii vo vremja Vtoroj russkoj smuty // Novyj istoricheskij vestnik. 2013. N 3 (37). P. 38-39.

Karpenko S.V. Jekonomicheskij krizis i korrupcija: Iz istorii tyla belyh armij juga Rossii (19181920 gg.) // Jekonomicheskij zhurnal. 2015. N 2 (38). P. 101-121.

Kokoulin V.G. «Ot mala do velika spekulirujut na chem tol'ko vozmozhno»: Gorodskie rynki v «beloj» Sibiri (1918-1919 gg.) // Novyj istoricheskij vestnik. 2012. N 3 (33). P. 94-109.

RGVA. F. 39515. Op. 1. D. 304. L. 271. 